\title{
Global and local corrosion of welded joints of high- strength low-alloy automotive steel
}

Mainã Portella Garcia,* Juliana Sarango de Souza,** Carol Glover, *** Phil Ansell,**** Geraint Williams, ${ }^{* * * *}$, Gerson Luiz Mantovani, ${ }^{* * * * *}$, Ramachandran Vasant Kumar,****** and Renato Altobelli Antunes $\stackrel{* * * * * * *}{*}$

${ }^{\ddagger}$ Corresponding author. E-mail: renato.antunes@ufabc.edu.br.

* School of Mechanical, Materials, Mechatronic and Biomedical Engineering, University of Wollongong, Wollongong, NSW 2522, Australia.

** Laboratório de Materiais e Manufatura Mecânica - (L3M), Universidade Federal de São Paulo (UNIFESP), 09910-720, Diadema, Brazil.

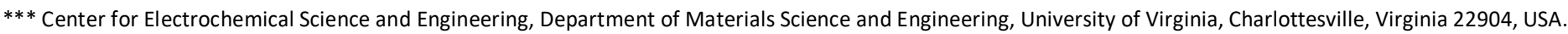

**** Materials Research Centre, College of Engineering, Swansea University, Bay Campus, Fabian Way, Crymlyn Burrows, Swansea, SA1 8EN, UK.

***** Centro de Engenharia, Modelagem e Ciências Sociais Aplicadas (CECS), Universidade Federal do ABC (UFABC), 09210-580, Santo André, SP, Brazil.

****** Department of Materials Science and Metallurgy, University of Cambridge, Cambridge CB3 OFS, UK.

\section{ABSTRACT}

Global and local corrosion techniques were used to study the corrosion behaviour of weld joints of a high strength low alloy steel (LNE500), typically employed in the automotive industry, in Brazil. The welded joints were prepared by gas metal arc welding (GMAW). Two welding transfer modes were used in order to obtain different heat inputs (HI): pulsed (PUL) and cold metal transfer (CMT). Local and global corrosion analysis techniques presented complementary information. While the local in-situ analysis (scanning vibrating electrode technique) revealed the weld metal (WM) as the region where corrosion started, conventional electrochemical techniques (Potentiodynamic polarization (PP) and electrochemical impedance spectroscopy (EIS)) revealed a higher corrosion rate in the coarse-grained heat affected zone (CGHAZ), which was preferentially corroded. A superior corrosion resistance of the weld metal obtained using CMT over the PUL transfer mode was revealed by EIS and PP. In addition, the results from CMT and PUL samples show that austenite grain size affects the propagation of the corrosion process. The results are discussed based on microstructural and compositional aspects of the different regions that characterize the welded joints.

KEY WORDS: EIS, high strength low alloy steel, polarization, SVET, welding.

\section{INTRODUCTION}

High-strength low-alloy (HSLA) steels are considered a breakthrough in the automotive industry [1]. Their alloy design and thermomechanical processing have helped guarantee an optimized microstructure, resulting in high strength, excellent weldability, good formability and weight reduction [2,3]. Good mechanical properties are achieved by grain refinement, solid solution strengthening and precipitation hardening [4]. Nevertheless, the carefully processed microstructure of HSLA steels may deteriorate during welding, one of the most important permanent joint processes for metallic materials [5].

The high temperature reached by the workpiece during fusion welding can drastically affect the surrounding base metal. The timetemperature profile experienced during welding changes along the distance from the fusion line, creating a steep temperature gradient which is dependent on the heat input (HI) of the welding process [6]. In general, weld joints exhibit three distinguishable regions, including base metal (BM), heat affected zone (HAZ) and weld metal (WM). In the HAZ adjacent to the weld pool, temperature generated by welding is high enough to 
completely austenitize the microstructure [7]. As is well-known, grain growth is driven by temperature [8]. Therefore, a coarse-grained heat affected zone (CGHAZ) is expected to develop adjacent to the weld pool.

This scenario can be even more complex if one considers that the joint behaviour is not only dependent on the microstructure and chemical composition of the base metal but also on the filler material used as weld metal. Such heterogeneous surface triggers the susceptibility to galvanic corrosion in the welded joint. Galvanic effects between WM, HAZ and BM may lead to preferential weld corrosion (PWC), contributing to mechanical failures and reduction in the lifetime of the component [9]. Preferential weld corrosion must be avoided because if the weld is preferentially dissolved, corrosion will be enhanced at the anodic zone by the unfavourable surface area ratio (e.g. (small anodic weld area) / (large cathodic base metal area)). PWC of iron-based alloys is usually controlled by using filler materials with the addition of nobler elements such as nickel, molybdenum, copper, or corrosion resistant elements such as aluminium, chromium and vanadium, responsible for decreasing the corrosion rate $[9,10]$.

The understanding of local corrosion process of welded joints can be complex [11]. The use of conventional corrosion techniques may not be enough to fully characterise the prevailing electrochemical processes. Therefore, certain scanning probe techniques, which provide spatially resolved information on time-dependent localised corrosion behaviour, may prove more effective in characterising welded joints. The scanning vibrating electrode technique (SVET) provides a means of measuring the magnitude and sign of current density distributions over freely corroding metal surfaces immersed in corrosive solution. SVET has been used to pinpoint regions of the weld which are most susceptible to breakdown and how subsequent cathodic activation of previously corroded areas influences the propagation of localised corrosion features [12-17].

Many publications are dedicated to study the corrosion experienced by weldments of steels employed in the oil and gas industry [18, 19]. However, only a very limited number is dedicated to understand the local corrosion behaviour of steels used in automotive applications [20].

In this work, two welding transfer modes are used to join a high-strength low-alloy automotive steel. The aim is to evaluate the corrosion resistance of the weld joint and understand the influence of the welding transfer mode in the corrosion behaviour. The local corrosion activity of the welded joint was investigated using SVET. The microstructure and grain size of the CGHAZ were characterized by optical microscopy and scanning electron microscopy (SEM). The electrochemical behaviour was assessed by conventional techniques (electrochemical impedance spectroscopy and potentiodynamic polarization).

\section{EXPERIMENTAL PROCEDURES}

\subsection{Material and welding process}

The material used in the present work was a hot rolled high-strength low-alloy (HSLA) steel with yield strength of 500 MPa produced by USIMINAS (named LNE500 - ABNT NBR6656). Its chemical composition is displayed in Table 1. The gauge length of the base metal (BM) was 6 mm. The BM samples were joined using gas metal arc welding (GMAW) and employing a $1.2 \mathrm{~mm}$-diameter filler wire metal whose composition is given in Table 1.

A V-groove joint design was used to weld the samples, with a $45^{\circ}$ included angle. The GMAW process was carried out by a Kuka Robot coupled to a Fronius arc welding machine. Two different transfer modes were chosen: pulsed (PUL) and cold metal transfer (CMT). Pulsed transfer is characterised by a pulsed current waveform and each current pulse detaches a droplet of the molten material. The droplet has a similar size to that of the wire (filler) diameter. In this mode, the transfer occurs when the wire dips into the weld pool and a short circuit occurs [21, 22]. However, when the short circuit occurs (when the droplet makes contact with the workpiece) the current increases, resulting in an explosive rupture of the wire and high levels of spatter. Controlled short arc - under market name CMT - overcomes this issue by controlling the wire motion automatically during droplet detachment. Therefore, these two modes were selected in order to assess the microstructural differences of the joints 
and, consequently, their effects on the corrosion process. The welding parameters were adjusted to obtain full penetration with no apparent defects. The welding parameters are shown in Table 2. The shielding gas was a mixture of $20 \% \mathrm{CO}_{2}$ and $80 \% \mathrm{Ar}$.

The heat input of each sample was calculated using Equation $1^{18}$. Where eff = Efficiency of heat transfer $(\%) ; E=\operatorname{arc~voltage~}(V) ; I=\operatorname{arc}$ current $(\mathrm{A})$; and $\mathrm{S}=$ welding speed $(\mathrm{mm} / \mathrm{s})$.

$$
H I=E f f \times\left(\frac{E \times I}{1000 \times s}\right)
$$

\subsection{Microstructural characterization}

After welding, sectioned samples were mounted, ground using silicon carbide ( $\mathrm{SiC}$ ) abrasive papers from grit 600 to 1200 and were mechanically polished with 1- $\mu \mathrm{m}$ diamond paste. The samples were chemically etched using Nital $2 \%$ to reveal their microstructures. Picric acid solution was also used to highlight prior austenite grains. The picric acid solution was prepared by mixing two solutions. Firstly, a saturated picric acid solution was prepared, adding $4 \mathrm{~g}$ of picric acid into $100 \mathrm{ml}$ ethanol (solution A). Secondly, $1 \mathrm{~g}$ of sodium metabisulfite was added into $100 \mathrm{ml}$ deionized water (solution B). Solution A was mixed with solution B in a 1:1 ratio immediately before etching. The samples were etched for $20-60 \mathrm{~s}$ at room temperature. Optical microscopy and scanning electron microscopy (SEM) (FEI Nova nanoSEM) set at an accelerating voltage of 23 kV were used for examining the microstructure. The prior austenite grain sizes of BM and HAZ were evaluated by the linear intercept method from optical micrographs ${ }^{21}$. The average of three readings is reported.

The prior austenite grain sizes of BM and HAZ were evaluated by the linear intercept method from optical micrographs, as ASTM E112-13 standard [25]. The average of three readings is reported.

A scanning transmission electron microscope (STEM) (FEI Tecnai Osiris 80-200) coupled with an energy dispersive X-ray spectroscopy (EDS) detector was used for characterization of precipitates at an accelerating voltage of $200 \mathrm{kV}$. Thin foil specimens were prepared from 0.3-0.6 $\mathrm{mm}$ thick slit parallelepiped using a cut-off wheel (Seccutom-10). Secondly, using a spark erosion machine and a copper wire, the parallelepiped specimens were cut down into $3 \mathrm{~mm}$ diameter discs. The disks were subsequently mechanically ground by hand to less than $0.1 \mathrm{~mm}$ thickness using $\mathrm{SiC}$ paper. Finally, the disks were thinned in a twin electropolishing unit using $5 \%$ perchloric acid in ethanol at $-20^{\circ} \mathrm{C}$. The voltage was adjusted to get the best polishing effect.

\subsection{Electrochemical tests}

Potentiodynamic polarisation (PP) and electrochemical impedance spectroscopy (EIS) were performed in a conventional three-electrode cell configuration, using an $\mathrm{Ag} / \mathrm{AgCl}(3 \mathrm{M}, \mathrm{KCl})$ reference electrode, a platinum wire as the counter-electrode and the steel samples as the working electrodes. The tests were carried out in $3.5 \mathrm{wt}$. \% NaCl solution at room temperature using an Autolab M101 potentiostat/galvanostat. Initially, the open circuit potential was monitored for $1 \mathrm{~h}$. Next, EIS measurements were performed at the open circuit potential, ranging the frequency from $100 \mathrm{kHz}$ up to $10 \mathrm{mHz}$ with an amplitude of the perturbation signal of $\pm 10 \mathrm{mV}$ (rms) and an acquisition rate of 10 points/decade. Right after the EIS measurements, PP curves were obtained by sweeping the potential from $-300 \mathrm{mV}$ versus the $0 \mathrm{CP}$ up to $+0.4 \mathrm{~V}_{\mathrm{Ag} / \mathrm{AgCl}}$ at a scanning rate of $1 \mathrm{mV} . \mathrm{s}^{-1}$. The electrochemical measurements were carried out according to three different configurations: i) by exposing the base metal (Fig. 1 a); ii) by exposing the whole welded joint, including WM and BM (Fig.1 b) and iii) by exposing solely the WM surface (Fig.1 c). On the configuration (iii), 
nail polish was used to cover the BM. It should be noted that the WM is the solidified wire after welding process. Figure $1 \mathrm{~d}$ shows an actual image of the welded joint.

Confocal laser scanning microscopy (CLSM) (Olympus LEXT OLS4100 microscope) was used to obtain 3D topographic images before and after the potentiodynamic polarisation tests. The corrosion product was removed by using a solution consisting of $100 \mathrm{~mL}$ deionized water and 100 $\mathrm{mL} \mathrm{HCl}(60 \%)$ for few seconds until the corrosion product was completely detached from the surface.

SVET measurements were performed on welded joint samples at room temperature. The working surface was covered with $90 \mu \mathrm{m}$ thick extruded PTFE tape (3M 5490), leaving only a rectangular square area centred on the welded region of the specimen exposed to the electrolyte. The probe vibration frequency was $140 \mathrm{~Hz}$ and the peak-to-peak vibration amplitude was $20 \pm 5 \mu \mathrm{m}$. The entirety of the exposed surface was scanned, with each individual scan taking roughly 40 min to complete. SVET experiments were carried out in 0.1 wt. \% NaCl solution. A preliminary test was carried out in $3.5 \mathrm{wt}$ \% $\mathrm{NaCl}$ solution, but corrosion happened too rapidly to clearly distinguish between anodic and cathodic local sites. Therefore, a less aggressive 0.1 wt. \% aqueous $\mathrm{NaCl}$ solution was employed. The active portion of the probe tip consisted of a $125 \mu \mathrm{m}$ diameter Pt microdisk electrode and the total tip diameter is $250 \mu \mathrm{m}$. The SVET probe was held vertically and scanned at a fixed height (100 $\mu \mathrm{m})$ above the working surface. A schematic representation of SVET configuration, including its probe can be found in a previous publication [26]. A macro photograph from every SVET samples was taken after the conclusion of the SVET experiments.

\section{RESULTS}

\subsection{Microstructural characterisation}

Fig. 2 (a) shows a typical optical microstructure of the base metal which consists of a fine grained ferrite matrix and pearlite islands. SEM images (Figs. $2 b-c$ ) confirm the lamellar structure of pearlite. The base metal was welded and the resulting microstructures of the heat-affected zone (HAZ) and weld metal (WM) are shown in Fig. 3.

In the CGHAZ (Figs. 3a-b), the microstructure shows up a typical bainitic ferrite structure with secondary micro-constituents such as martensite-austenite islands and $\mathrm{TiNb}(\mathrm{CN})$ particles identified by SEM and presented in Fig. 4 (a). The microstructure of the WM is composed of acicular ferrite and grain boundary ferrite - as brighter regions (Figs. 3c-d). In Fig. 4 (b), STEM reveals inclusions in the WM for both samples (Figs. 4a-b). These inclusions are well distributed in the weld zone and they are well-known as nucleation sites to promote acicular ferrite formation.

The typical composition of the inclusions found in the WM is displayed in Figure 4a. The inclusions are oxides composed of deoxidizing elements such as silicon, manganese, aluminium, and titanium. A layer rich of $\mathrm{Cu}$ covering part of the oxide was found in some cases. HAZ immediately adjacent to the fusion boundary is heated up to very high temperatures and, hence, can transform completely to austenite. Consequently, the austenite that forms is subject to elevated temperatures, giving rise to a coarse-grained structure (CGHAZ) ${ }^{7}$. Fig. 5 shows the prior austenite grains on the CGHAZ for PUL and CMT samples. As expected, the grain size falls monotonically with the distance from the fusion line. Austenite grain size values are presented in Table 3. For CMT sample, the average grain size was $40 \mu \mathrm{m}$ whereas PUL sample was $55 \mu \mathrm{m}$. The former showed a more homogeneous grain size distribution. This fact confirms that the heat input of CMT sample was much lower than the heat input in the PUL sample.

In addition, chemical analysis for the different joint zones (i.e. WM and CGHAZ) was performed by EDS. The results are shown in Table 4. What is interesting about the data in Table 4 (post welding) is the difference when compared to the chemical composition prior to the welding process (Table 1). Although the quantitative accuracy of EDS analysis can be discussed [28-30] qualitative information supported by literature reports can indeed provide indication of higher content elements. 
There is considerably less Si in WM compared to the filler material. The decrease in Si content is expected under welding condition, i.e. at elevated temperature, because $\mathrm{Si}$, as a deoxidizing element, combines with oxygen forming $\mathrm{SiO}_{2}$. Once the weld cools, $\mathrm{SiO}_{2}$ diffuses to the surface ${ }^{23}$. Thus, only half of Si content is identified in the WM. Likewise, copper decreased significantly. Cu content in the filler, prior to the welding was 0.141 wt. \%, after welding the Cu content in the WM was only $0.09 \mathrm{wt}$. \%. It is worth noting that the majority of copper in the filler material is present in the coating of the filler wire. During the transfer of the molten droplet, at high temperatures, part of the copper present in the coating is vaporised $^{24}$. Moreover, $\mathrm{Cu}$-rich inclusions were also identified in the WM (see Fig. 4b), which contributes to the average decrease of Cu in the WM. In contrast, in the CGHAZ the copper content increased from 0.005 wt. \% (BM) to 0.06 wt. \% (CMT) and 0.03 wt. \% (PUL). It is assumed that part of the copper diffused from the filler wire to the CGHAZ during the WM solidification. The main compositional different of CGHAZ and WM is the Si content, which is much higher in the WM.

\subsection{Electrochemical characterisation}

\subsubsection{Conventional techniques}

a) Open circuit potential

The open circuit potential (OCP) was monitored as a function of the immersion time in $3.5 \mathrm{wt} \% \mathrm{NaCl}$ solution at room temperature for the BM, WM and welded joints. The results are displayed in Fig. 5. All curves present an initial drop of the OCP with time, followed by a stabilisation trend. There is a noticeable different between the OCP values of the welded joints and those of the BM and WM samples after stabilization. The OCP is shifted towards more negative values for the welded joints with respect to the BM and WM samples. The OCP of the welded joint_PUL sample is $-611 \mathrm{mV}_{\mathrm{Ag} / \mathrm{AgCl}}$ and that of the welded joint_CMT sample is $-635 \mathrm{mV}_{\mathrm{Ag} / \mathrm{AgCl}}$. When the isolated welded metal zones were measured, the OCP values were less negative $\left(-566 \mathrm{mV}_{\mathrm{Ag} / \mathrm{AgCl}}\right.$ for the $\mathrm{WM}$ _PUL and $-580 \mathrm{mV}_{\mathrm{Ag} / \mathrm{AgCl}}$ for the WM_CMT, according to Fig. 5), close to that of the BM (-576

$\mathrm{mV}_{\mathrm{Ag} / \mathrm{AgCl}}$. The results show, therefore, that the welded joints present a higher electrochemical activity with respect to the $\mathrm{BM}$ and $\mathrm{WM}$ samples. The main difference between the BM, WM and the whole welded joints is related to the presence of the CGHAZ in the welded joints. It is likely that the potential shift of the welded joint samples toward less noble values is related to the CGHAZ. Furthermore, it is also noteworthy that the electrochemical activity of the CMT samples (both WM_CMT and Welded joint_CMT) is higher (more negative potentials) than that of the PUL counterparts (WM_PUL and Welded joint_PUL). This could be an effect of the higher electrochemical activity associated with the smaller grain sizes of the CGHAZ for the CMT sample (Table 3) that leads to a higher density of grain boundaries (interfacial defects).

b) Electrochemical impedance spectroscopy (EIS)

Figures 6 and 7 show the Nyquist and Bode plots, respectively, for the three different sample configurations (i.e. Welded joint, weld metal only (WM) and base metal (BM)). The tests were carried out in $3.5 \mathrm{wt}$. \% NaCl solution at room temperature. Figure 8 shows the electrical equivalent circuits (EECS) used to fit the experimental EIS data. Constant phase elements were employed instead of pure capacitors to account for surface heterogeneities [33]. The impedance of a $C P E\left(Z_{C P E}\right)$ is given by $Z_{C P E}=\left[Q(j \omega)^{n}\right]^{-1}$, where $j$ is the complex operator, $\omega$ is the angular frequency, $Q$ is the CPE capacitance and $n$ its exponent $(n=1$ for an ideal capacitor, $n=0$ for a pure resistive behaviour and $0<n<1$ for imperfect capacitive behaviour) [34]. Fitting parameters are displayed in Table 5. Two different models were adopted to fit the data. The first EEC shown in Fig. 8a was employed only for the base metal (BM). It consists of two time constants. The physical meaning of each circuit parameter is given as follows: $R_{e}$ is the electrolyte resistance; $R_{o x}$ is the resistance of surface oxide film and $Q_{o x}$ is associated with its capacitance; $R_{c t}$ is the charge transfer resistance and $Q_{d l}$ is related to the double layer capacitance. This type of EEC is often adopted to model the EIS response of an electrode when its surface is covered with an oxide film [35]. The circuit shown in Fig. 8b provided best fitting to the EIS response of the welded joints and WM samples. The elements in this circuit have the same physical meaning as those previously mentioned for the BM. It consists of one single time constant, accounting for the free corrosion of the electrode surface, as frequently reported for different steels in sodium chloride solutions [36,37]. 
Nyquist plots are characterized by one single capacitive loop for the WM and welded joints, with imperfect semicircles. The BM sample, in turn, presents two time constants. The size of the capacitive loop in Nyquist plots is related to the magnitude of the charge transfer resistance and, therefore, to the corrosion resistance of the electrode surface [38]. Similar semicircle diameters are observed for the welded joints CMT and PUL (Fig. 6a), whereas weld metal samples present some differences. The nominal semicircle diameter for the WM_CMT is larger which reflects its better corrosion resistance than that of the sample welded using the pulsed transfer mode (WM_PUL) (Fig. 6b). The BM semicircle diameter is much smaller than those obtained for the welded joints, indicating the relatively poor corrosion resistance of the base metal. The $R_{\mathrm{ox}}$ value of the

BM sample (Table 5) is very small, revealing that, in spite of the presence of a surface oxide layer, it does not have a protective character against corrosion. The values of $R_{c t}$ shown in Table 5 clearly indicate the lower corrosion resistance of the BM when compared to the other samples. Bode plots ( $\log |\mathrm{Z}|$ vs. $\log \mathrm{f})$ are shown in Fig. 7, confirming the relatively low absolute impedance of the BM sample when compared to the WM and welded joints. Based on the phase angle diagrams (Fig. 7), there were no significant differences between the shapes of the plots for all samples, suggesting the corrosion mechanism was not altered after welding. The two time constants of the BM are likely to be overlapped in Fig. 7a. There is a slight decrease of the peak phase angles of the BM toward less capacitive values when compared to the welded joints (Fig. 7a), suggesting loss of capacitive response and lower corrosion resistance than the welded joints. When the WM_PUL and WM_CMT samples phase angles are compared (Fig. 7b), a small decrease of the peak phase is realized for the WM_PUL, as well as a slight shift of the peak to lower frequencies, indicating its lower corrosion resistance, as denoted by the relatively lower Rct value compared to that of WM_CMT (Table 5).

c) Potentiodynamic polarisation curves

Polarisation curves shown in Fig. 9 reveal typical active corrosion behaviour for all samples, without passivation, as reported for several types of carbon steels and alloy steels $[39,40]$. The active corrosion behaviour is indicated by the continuous increase of the current density as the applied potential is further increased. The corrosion potential can be used to evaluate the stability of the electrode with regard to the onset of corrosion processes. More positive values of are related to lower electrochemical activity [41]. In agreement with Figure 5, the corrosion potentials of the welded joints are lower when compared to BM and WM samples. The corrosion potentials of the PUL samples (WM and welded joints) are higher than their CMT counterparts.

The electrochemical behaviour observed in Fig. 9 is consistent with a mixed corrosion control where the anodic process is under activation and the cathodic reaction $\left(\mathrm{O}_{2}+2 \mathrm{H}_{2} \mathrm{O}+4 \mathrm{e} \leftrightarrow 4 \mathrm{OH}^{-}\right)$presents a mixed activation-concentration effect. The concentration effect becomes dominant for potentials below $60 \mathrm{mV}$ with respect to the corrosion potential. This behaviour is common to all samples. As anodic and cathodic reactions are not purely activation-controlled, it is not suitable to use the Tafel extrapolation method to obtain the corrosion current density [39]. Notwithstanding this limitation, it is interesting to observe that the polarisation curves are shifted to higher current densities for the BM and WM samples when compared to the Welded joint_PUL and Welded joint-CMT, indicating their higher corrosion kinetics. The lowest current densities were measured for the Welded joint_CMT.

\subsubsection{Confocal laser scanning microscopy (CLSM)}

Before polarisation tests all samples were polished. One sample was etched with Nital and its surface was captured by CLSM. As can be seen the sample surface was flat (Fig. 10a). Fig. 10b shows the corroded surface after polarisation experiments. Figs.10 (c-d) show the samples surface after removing the corrosion products, revealing a depth difference between BM/CGHAZ and WM.

A non-uniform corrosion is observed along the joints. CGHAZ was more intensely corroded than WM. Considering the average values, the depth difference between HAZ and WM was $30 \mu \mathrm{m}$ and $22 \mu \mathrm{m}$ for samples PUL and CMT, respectively. Moreover, the boundary between HAZ and WM (i.e. the fusion line) was the region more intensely corroded for PUL and CMT samples (maximum values of depth difference). These results 
are in agreement with the OCP curves shown in Fig. 5 that gave an indirect indication of the higher electrochemical activity of the CGHAZ with respect to the WM zone for both the PUL and CMT samples.

\subsubsection{SVET}

Figures 9 and 10 show a series of SVET maps, recorded at different immersion times in the absence of external polarisation, showing current density $\left(\mathrm{i}_{\mathrm{z}}\right.$ ) distributions over PUL and CMT welded joints, respectively, upon immersion in 0.1 wt. \% NaCl (aq). In SVET measurements spatial variation of current density $\left(i_{z}\right)$ is mapped. The blue colour represents negative current densities (cathodic regions), whilst red colour presents positive current densities (anodic regions). The first scan recorded, for both samples, intense local anodic activity regions (red dots) mainly in the WM. Indeed, more red dots are observed in the PUL sample in the earlier stages of the corrosion process, first scan in Fig. 9. The red dots occur between precipitates/inclusion (Fig. 4) and matrix. SVET is sensitive enough to detect this slight difference in the electrochemical behaviour of each sample. Subsequent scans show corrosion spreading across the whole surface for PUL specimen (Fig. 9). However, for the CMT specimen

(Fig. 10), corrosion does not spread into the HAZ beyond over the same immersion time and preferable corrosion happens in the WM over the whole test.

It important to note that some red dots in HAZ/BM region visible at the first minutes are no longer visible after $18 \mathrm{~h}$ in $\mathrm{CMT}$ sample, suggesting it presents repassivation ability. This behavior was less remarkable for the PUL sample.

Images obtained after the SVET measurement revealed an orange film on top of the corroded area. This film is generally composed of iron hydroxides that are poorly protective due to its non-adherent character ${ }^{27}$. Low-alloy steels are essentially alloyed with low contents of passivating elements such as $\mathrm{Cr}$. Thus, due to their low content, they do not produce a protective film. Instead, an Fe oxide layer can be formed on their surface, typically ferric oxyhydroxide (FeOOH). This rust film is highly porous and weakly adhered to the substrate, allowing the electrolyte to penetrate through it. and reach the underlying steel, leading to continuous corrosion processes and high rates of material loss ${ }^{28}$. In relation to that, SVET tests reveal an increase in the peak current density in the first minutes of immersion, followed by a decrease over the time, which can be explained by the approximation of the potentials of the cathodic and anodic regions, probably caused by the influence of corrosion products ${ }^{29}$. The rust covered regions correspond to areas which were revealed by SVET as local net anodic sites.

\section{DISCUSSION}

The weld joint surface is metallurgically non-uniform, thus heterogeneous electrochemical regions form, promoting corrosion. The welded samples analysed in this study were fabricated using the same base metal and filler. However, samples were welded using different transfer modes, which generated different thermal cycles. Ultimately, the thermal cycle directly affects the final microstructure of the HAZ. The region where austenite grain coarsens (i.e. CGHAZ) presented a significant difference in the austenite grain size for the CMT and PUL transfer modes. An increased grain coarsening in the CGHAZ region was observed for the PUL sample. This feature reveals that the actual heat affecting the sample welded with pulse transfer mode was greater than in the CMT, producing a coarser microstructure.

In this study, two complementary information could be obtained about the corrosion process of the welded samples. Conventional electrochemical techniques reveal the location where corrosion is faster, whereas SVET analysis reveals the preferential sites where corrosion initiates. In addition, the results from CMT and PUL samples show that austenite grain size affects the propagation of the corrosion process.

\subsection{Potentiodynamic Polarisation (PP) and Electrochemical Impedance Spectroscopy (EIS) tests}


PP and EIS experiments provided the opportunity to quantify galvanic effects at the welded joint and to measure the corrosion currents across it. Such information provided a reliable indication of the expected corrosion performance of the welded joint when in service.

It was verified that the $\mathrm{i}_{\text {corr }}$ and $\mathrm{E}_{\text {corr }}$ values of the welded joints obtained by CMT and PUL transfer modes were very similar (Table 6). But some differences were detected when studying the electrochemical behavior at isolated WM regions. The PP tests at WM samples revealed a higher higher corrosion current density (faster corrosion) for the PUL sample when compared to CMT.

CLSM analysis (Fig. 8) showed that both samples had preferential corrosion in the CGHAZ, which is preferable as it avoids preferential corrosion in the weld. The difference in depth between CGHAZ and WM was 30 and $22 \mu \mathrm{m}$ for PUL and CMT, respectively. The sample with coarser austenite grain size (PUL) in the CGHAZ and higher $\mathrm{i}_{\text {corr }}$ in the WM had a slight higher depth compared to CMT sample, indicating its lower corrosion resistance. Therefore, it is inferred, based on the CLSM images, that the HAZ region in general had an elevate corrosion rate compared to the WM region.

As the chemical compositions and microstructures of the HAZ and WM regions do not differ for the PUL and CMT modes, their distinct corrosion behaviors are believed to be related to the austenite grain size. The coarse austenite grain size in the CGHAZ of the PUL sample would imply in a higher corrosion rate. Indeed, it is reported that for low carbon steels in similar solution (3.5 wt. \% $\mathrm{NaCl}$ aq.), the grain boundaries firstly suffered severe corrosion because of the higher activity ${ }^{30}$. The grain boundaries are well-known to be rich in certain elements such as $\mathrm{C}$ and $\mathrm{Nb}^{31}$. In the case of smaller grain sizes (i.e. CMT specimen), there is an increase in grain boundary area per unit volume which leads to boundaries with lower concentration of alloying elements. Thus, a more homogenous grain boundary chemical composition may improve the corrosion resistance of the CMT sample.

Some authors have correlated the grain size and the electrochemical behaviour of metallic alloys $[13,45]$. HAZ was reported as having low corrosion resistance due to its coarse microstructure, and high residual stress [45]. Kish and collaborators studied friction stir welded Mg alloy joints. They found that the grain size affects the initiation of the corrosion process but does not affect its propagation [13]. The welding process chosen in their study does not require the addition of a second material (filler). Therefore, there is no chemical difference among WM and HAZ. In the case of arc welding, in which a filler is used, the assessment of the grain size effect on the corrosion process over weld joints is not easy due to the great number of variables that affect the corrosion behaviour, such as chemical composition and microstructure. In other words, it is hard to exclude other effects and solely study the influence of austenite grain size. Although the present study involves a filler as second material, the difference in the grain size seems to affect the propagation of the corrosion process. The corrosion rate in the CGHAZ of the PUL sample (larger grains) was higher than the CMT sample (smaller grain sizes).

During a failure investigation of low carbon steel, it was detected that the microstructural variations in the weld joint resulted in galvanic feature leading to failure and rupture of the weld joint during the service ${ }^{32}$. The HAZ due to the local stresses and lattice defects was reported as having the lowest corrosion resistance ${ }^{32}$. The high temperatures of the welding process and subsequent cooling is responsible for generating microstructural and microhardness variations in the weld joint, producing local stresses ${ }^{32}$.

Additionally, the chemical compositions of WM and HAZ were examined by EDS analysis. WM was mainly richer in Si (0.35 wt. \%) introduced preferentially from the filler material in both CMT and PUL samples. Other elements such as $\mathrm{Mn}, \mathrm{Cr}$ and $\mathrm{Cu}$ were detected with similar values for both regions and $\mathrm{Nb}$ was only detected in the HAZ. The higher Si content may be also enhancing the cathodic behaviour of the WM. In fact, it has been reported that minor Si additions (via the filler) are beneficial for decreasing corrosion ${ }^{33}$.

\section{2 -SVET tests}


SVET experiments provided the opportunity to visualise the local galvanic effects and to measure the localized corrosion current across the welded joint, revealing the preferential sites of the welded joints where corrosion began.

Over the welded surfaces, negative (cathodic) and positive (anodic) ionic current densities were detected by SVET. Initially, anodic peak current densities were captured in the WM, representing a region that is preferentially corroded and where corrosion started. After a while, corrosion spread along the surface of the HAZ and BM for the PUL sample but not for CMT.

As mentioned before, the main difference between PUL and CMT samples is the austenite grain size in the CGHAZ due to the HI generated in each mode. The PUL sample was exposed to the highest heat input (HI) during the welding process and, as a consequence, coarser grains were observed in the CGHAZ. The SVET was effective at detecting high active corrosion spots across the welded joints.

It is believed that some active points measured by SVET in the welded joints may be the oxide inclusions and carbonitride precipitates that were detected by STEM (Fig. 3). Even though a shielding gas is used during GMAW in order to protect the weld pool, the protection is not entirely effective, which permits these oxide particles being entrapped in the fusion zone during solidification. The TiNb(CN) have a high temperature stability and will resist to the welding processing [50].

It is known that precipitates composed by oxides, carbides or nitrides induce anodic sites formation in the steel microstructure [51-55] Non-metallic inclusions at the matrix structure interface are not only incoherent, but they also exhibit different corrosion potentials than the steel microstructure, thus leading to the formation of microgalvanic couples. Corrosion is initiated at the vicinity of the non-metallic inclusions [56-58]. This way, the local anodic activity is provided by different chemical composition among precipitates/inclusions and matrix responsible for starting the local corrosion spots. The potential difference generated by galvanic coupling in the welded joint is greater among precipitates and WM than for precipitates and HAZ, justifying that local corrosion spots firstly appear in the WM region.

Comparing the HAZ regions of the PUL and CMT samples, the grain size in the CGHAZ is the main factor that could explain the differences in corrosion propagation. By increasing the grain boundary area per unit volume, a homogenous chemical composition is favoured at the grain boundaries, thus decreasing the corrosion susceptibility. Furthermore, a greater re-passivation capacity was observed for the CMT sample, which may also be related to finer grains and/or finer precipitates. Repassivation over longer times restrains corrosion initiation in this region.

In addition, a more intense anodic activity is observed in PUL sample than CMT sample after the same period under NaCl immersion (Figs 11 and 12, respectively). The higher current density for the same immersion period also shows the higher local corrosion rate following its initiation, revealing a greater severity of corrosion for sample welded with PUL mode. Once again, the effect of grain size is associated with propagation of the corrosion.

A deeper analysis of austenite grain boundaries chemistry and a quantitative analysis of the precipitates in the HAZ is necessary to further identification of the differences between both welded specimens with different transfer modes.

\section{CONCLUSIONS}

The corrosion behaviour of two welded joints of a high strength-low alloy automotive steel was investigated. Two different welding transfer modes (pulse-PUL and cold metal transfer-CMT) were used, generating different heat inputs. The main microstructural differences observed in both samples were related to the austenite grain size. PUL sample which was welded with larger heat input had larger austenite grains 
size in the coarse-grained heat affected zone (CGHAZ). EIS and PP tests revealed the largest corrosion rates on the base metal (BM) sample, suggesting that BM and HAZ were more susceptible to general corrosion. This fact was confirmed by confocal laser scanning microscopy, showing that CGHAZ was more deteriorated by corrosion. SVET measurements provided a current density mapping of the whole joint, encompassing BM/HAZ/WM regions, revealing that the WM was more prone to the onset of corrosion for both types of weld transfer modes. The sample with coarser austenite grain size obtained by pulse mode was more severely corroded than the sample welded with CMT mode.

\section{ACKNOWLEDGMENTS}

Thanks due to Dr. Frank Barbaro and Matthew Franklin from University of Wollongong for the picric acid etching for austenite grain size measurement. Brazilian agency CNPq is acknowledged for the financial support.

\section{REFERENCES}

1. Garcia, C.I., High strength low alloyed (HSLA) steels, in Automotive Steels, R. Rana and S.B. Singh, Editors. 2017, Woodhead Publishing. p. 145-167.

2. Patel, J.K. and B. Wilshire, The challenge to produce consistent mechanical properties in Nb-HSLA strip steels. Journal of Materials Processing Technology, 2002. 120(1): p. 316-321.

3. Shao, Y., et al., Formation mechanism and control methods of acicular ferrite in HSLA steels: A review. Journal of Materials Science \& Technology, 2018. 34(5): p. 737-744.

4. Cochrane, R.C., Phase transformations in microalloyed high strength low alloy (HSLA) steels, in Phase Transformations in Steels, E. Pereloma and D.V. Edmonds, Editors. 2012, Woodhead Publishing. p. 153-212.

5. Kah, P. and J. Martikainen, Current trends in welding processes and materials: Improve in effectiveness. Reviews on Advanced Materials Science, 2012. 30(189-200).

6. Shi, Y., et al., HAZ microstructure simulation in welding of a ultra fine grain steel. Computational Materials Science, 2004. 31(3): p. 379388.

7. Bhadeshia, H.K.D.H. and R.W.K. Honeycombe, Steels: microstructure and properties. $4^{\text {th }}$ ed. 2017: Elsevier/Butterworth-Heinemann.

8. Moon, J., J. Lee, and C. Lee, Prediction for the austenite grain size in the presence of growing particles in the weld HAZ of Ti-microalloyed steel. Materials Science and Engineering: A, 2007. 459(1): p. 40-46.

9. Mahajanam, S.P.V. and M.W. Joosten, Selection of filler materials to minimize preferential weld corrosion in pipeline steels, in SPE Internation Conference on Oilfield Corrosion. 2010, Society of Petroleum Engineers: Aberdeen, UK. p. 82-92.

10. Lu, Y., et al., Recommend design of filler metal to minimize carbon steel weld metal preferential corrosion in CO2-saturated oilfield produced water. Applied Surface Science, 2016. 389: p. 609-622.

11. Eliyan, F.F. and A. Alfantazi, Corrosion of the Heat-Affected Zones (HAZs) of API-X100 pipeline steel in dilute bicarbonate solutions at $90{ }^{\circ} \mathrm{C}$ - An electrochemical evaluation. Corrosion Science, 2013. 74: p. 297-307.

12. Kish, J., et al., Corrosion Performance of Friction Stir Linear Lap Welded AM60B Joints. JOM: The Journal of The Minerals, Metals \& Materials Society (TMS), 2017. 69(11): p. 2335-2344.

13. Kish, J.R., et al., Effect of Grain Size on the Corrosion Resistance of Friction Stir Welded Mg Alloy AZ31B Joints. Journal of The Electrochemical Society, 2014. 161(9): p. C405-C411.

14. Zhang, G.A. and Y.F. Cheng, Micro-electrochemical characterization of corrosion of welded X70 pipeline steel in near-neutral pH solution. Corrosion Science, 2009. 51(8): p. 1714-1724.

15. Akid, R., et al., Application of scanning vibrating electrode technique (SVET) and scanning droplet cell (SDC) techniques to the study of weld corrosion, in Local Probe Techniques For Corrosion Research. 2007, European Federation of Corrosion by Woodhead Publishing and Maney PublishingWoodhead Publishing in Materials. p. 23. 
16.

Bertoncello, J.C.B., S.M. Manhabosco, and L.F.P. Dick, Corrosion study of the friction stir lap joint of AA7050-T76511 on AA2024-T3 using the scanning vibrating electrode technique. Corrosion Science, 2015. 94: p. 359-367.

17. Voruganti, V.S., et al., Scanning Reference Electrode Technique for the Investigation of Preferential Corrosion of Weldrnents in Offshore Applications. CORROSION, 1991. 47(5): p. 343-351.

18. Zhao, W., et al., Corrosion behavior of reheated CGHAZ of X80 pipeline steel in H2S-containing environments. Materials \& Design, 2016. 99: p. 44-56.

19. Alizadeh, M. and S. Bordbar, The influence of microstructure on the protective properties of the corrosion product layer generated on the welded API X70 steel in chloride solution. Corrosion Science, 2013. 70: p. 170-179.

20. Wint, N., et al., The galvanic corrosion of welded ultra-high strength steels used for automotive applications. Corrosion Science, 2018. 136: p. 366-373.

21. Pépe, N., et al., Measuring the process efficiency of controlled gas metal arc welding processes. Science and Technology of Welding and Joining, 2011. 16(5): p. 412-417.

22. Wainer, E., S.D. Brandi, and F.D.H. Mello, Soldagem: processos e metalurgia, Blucher, 1992.

23. ISO, 15614-1:2017 - Specification and qualification of welding procedures for metallic materials, in Welding procedure test - Part 1: Arc and gas welding of steels and arc welding of nickel and nickel alloys. 2017.

24. Quintino, L., et al., Heat input in full penetration welds in gas metal arc welding (GMAW). The International Journal of Advanced Manufacturing Technology, 2013. 68(9): p. 2833-2840.

25. ASTM, E112-13 - Standard test methods for determining average grain size, 2013.

26. Williams, G. and H.N. McMurray, Localized Corrosion of Magnesium in Chloride-Containing Electrolyte Studied by a Scanning Vibrating Electrode Technique. Journal of The Electrochemical Society, 2008. 155(7): p. C340-C349.

27. Loder, D. and S.K. Michelic, Systematic investigation of acicular ferrite formation on laboratory scale. Materials Science and Technology, 2017. 33(2): p. 162-171.

28. Y., L., Accuracy of EDS Quantification, in Practical Electron Microscopy and Database 2006, www.globalsino.com/EM/. p. 2513.

29. Newbury, D.E. and N.W.M. Ritchie, Is Scanning Electron Microscopy/Energy Dispersive X-ray Spectrometry (SEM/EDS) Quantitative? Scanning, 2013. 35: p. 141-168.

30. Miler, M. and B. Mirtic, Accuracy and precision of EDS analysis for identification of metal-bearing minerals in polished and rough particle samples. Geologija, 2013. 56(1): p. 005-018.

31. Bhadeshia, H.K.D.H. and L.E. Svensson, Modelling the Evolution of Microstructure in steel weld metal, in Mathematical Modelling of Weld Phenomena, H. Cerjak and K.E. Easterling, Editors. 1993, Institute of Materials: London. p. 109-182.

32. Bothma, N.C., The influence of copper coating on the fume formation rate of carbon steel welding wire during the gas metal arc welding process, in School of Mechanical, Materials and Mechatronic Engineering, PhD thesis, University of Wollongong, 2012.

33. De Motte, R., Basilico, E., Mingant, R., Kittel J., Ropital, F., Combrade, P., Necib, S., Deydier, V., Crusset, D. and Marcelin, S., A study by electrochemical impedance spectroscopy and surface analysis of corrosion product layers formed during CO2 corrosion of low alloy steel. Corrosion Science, 2020. 172: 108666-1-108666-14.

34. Guo, L., Huang, Q., Zhang, C., Wang, J., Shen, G., Ban, C. and Guo, L., Study on the formation of Mn-P coatings with significant corrosion resistance on Q235 carbon steels by adjusting the ratio of phosphorus to manganese. Corrosion Science, 2021. 178: 108960-1-108960-14.

35. Zhuang, S., Kainuma, S., Yang, M., Haraguchi, M. and Asano, T., Characterizing corrosion properties of carbon steel affected by high-power laser cleaning. Construction and Building Materials, 2021. 274: 122085-1-122085-11.

36. Neetu, Katiyear, P.K., Sangal, S. and Mondal, K., Effect of various phase fraction of bainite, intercritical ferrite, retained austenite and pearlite on the corrosion behavior of multiphase steels. Corrosion Science, 2021. 178: 109043-1-109043-17.

37. Moon, A.P., Sangal, S., Layed, S., Giribaskar, S. and Mondal, K., Corrosion behavior of high-strength bainitic rail steels. Metallurgical and Materials Transactions A, 2015. 46: 1500-1518.

38. Orazem, M.E. and B. Tribollet, Electrochemical Impedance Spectroscopy. 2nd ed. 2017, Hoboken, New Jersey: John Wiley \& Sons, Incorporated. 712. 
39. Wang, P., Ma, L., Cheng, X. and Li, X., Effect of grain size and crystallographic orientation on the corrosion behaviors of low alloy steel. Journal of Alloys and Compounds, 2021. 857: 158258-1-158258-9.

40. Li, J., Wu, J., Wang, Z., Zhang, S., Wu, X., Huang, Y. and Li, X., The effect of nanosized NbC precipitates on electrochemical corrosion behavior of high-strength low-alloy steel in 3.5\% NaCl solution. International Journal of Hydrogen Energy, 2017. 42: 22175-22184.

41. Ríos, C.T., J.S. de Souza, and R.A. Antunes, Preparation and characterization of the structure and corrosion behavior of wedge mold cast Fe43.2Co28.8B19.2Si4.8Nb4 bulk amorphous alloy. Journal of Alloys and Compounds, 2016. 682: p. 412-417.

42. Pagotto, J.F., et al., Visualisation of the Galvanic Effects at Welds on Carbon Steel. Journal of the Brazilian Chemical Society, 2015. 26: p. 667-675.

43. Guo, Y.-b., et al., Effect of microstructure variation on the corrosion behavior of high-strength low-alloy steel in 3.5wt\% NaCl solution. International Journal of Minerals, Metallurgy, and Materials, 2015. 22(6): p. 604-612.

44. López-Ortega, A., et al., Influence of temperature on the corrosion and tribocorrosion behaviour of High-Strength Low-Alloy steels used in offshore applications. Tribology International, 2018. 121: p. 341-352.

45. Wang, L.W., et al., In situ corrosion characterization of simulated weld heat affected zone on API X80 pipeline steel. Corrosion Science, 2014. 85: p. 401-410.

46. Ren, R.K., et al., A novel observation of the interaction between the macroelastic stress and electrochemical corrosion of low carbon steel in 3.5wt\% NaCl solution. Electrochimica Acta, 2012. 85: p. 283-294.

47. Wang, H.H., et al., Characterization of $\mathrm{Nb}$ Interface Segregation During Welding Thermal Cycle in Microalloyed Steel by Atom Probe Tomography. Metallurgical and Materials Transactions A, 2018. 49(12): p. 6224-6230.

48. Shirinzadeh-Dastgiri, M., et al., Metallurgical investigations and corrosion behavior of failed weld joint in AISI 1518 low carbon steel pipeline. Engineering Failure Analysis, 2015. 53: p. 78-96.

49. Li, Y.S., M. Spiegel, and S. Shimada, Effect of Al/Si addition on $\mathrm{KCl}$ induced corrosion of 9\% $\mathrm{Cr}$ steel. Materials Letters, 2004. 58(29): $\mathrm{p}$. 3787-3791.

50. Graux, A., et al., Precipitation and grain growth modelling in Ti-Nb microalloyed steels. Materialia, 2019. 5: p. 100233.

51. Michelic, S.K., et al., Characterization of TiN, TiC and Ti(C,N) in titanium-alloyed ferritic chromium steels focusing on the significance of different particle morphologies. Materials Characterization, 2015. 100: p. 61-67.

52. Baker, M.A. and J.E. Castle, The initiation of pitting corrosion of stainless steels at oxide inclusions. Corrosion Science, 1992. 33(8): p. $1295-1312$.

53. Demiroren, $\mathrm{H}$., et al., The corrosion characterization of a ferritic stainless steel with $\mathrm{Mo}$ addition in $\mathrm{H} 2 \mathrm{SO} 4$ and $\mathrm{HCl}$ acid solutions. Protection of Metals and Physical Chemistry of Surfaces, 2009. 45(5): p. 628-634.

54. Leban, M.B. and R. Tisu, The effect of TiN inclusions and deformation-induced martensite on the corrosion properties of AISI 321 stainless steel. Engineering Failure Analysis, 2013. 33: p. 430-438.

55. Zheng, S., et al., Mechanism of (Mg,Al,Ca)-oxide inclusion-induced pitting corrosion in $316 \mathrm{~L}$ stainless steel exposed to sulphur environments containing chloride ion. Corrosion Science, 2013. 67: p. 20-31.

56. Niclas, Å., K. Andrey, and J. Pär Göran, The Effect of Different Non-Metallic Inclusions on the Machinability of Steels. Materials, 2015. 8(2): p. $751-783$.

57. Wranglen, G., Pitting and sulphide inclusions in steel. Corrosion Science, 1974. 14(5): p. 331-349.

58. Bae, S.H. and H.W. Lee, Effect of Mo contents on corrosion behaviors of welded duplex stainless steel. Metals and Materials International, 2013. 19(3): p. 563-569. 


\section{FIGURE CAPTIONS}

FIGURE 1: Nomenclature and schematic representation of sample configurations (exposed surface of working electrode) for EIS and PP measurements (a) BM, (b) welded joint: WM+BM and (c) WM. [BM: base metal, WM: weld metal]; d) Actual image of the welded joint.

Figure 2: Microstructure of the BM HSLA500 (a) optical and (b) SEM micrographs, CGHAZ and WM of PUL (c-d) sample and CMT (e-f) sample, optical micrographs.

FIGURE 3: Typical precipitates found in the CGHAZ and WM. (a) SEM micrograph with EDS chemical composition (b) STEM micrograph STEM/EDS mapping analysis.

FIGURE 4: Optical micrographs of the boundary between WM and HAZ showing prior austenite grain (a-b) PUL and (c-d) CMT. Samples were etched with picric acid solution to reveals prior austenite grain size.

FIGURE 5: Variation of the open circuit potential with the time of immersion in $3.5 \mathrm{wt} . \% \mathrm{NaCl}$ solution.

FIGURE 6: Nyquist plots for a) welded joints and BM and b) WM samples in $3.5 \mathrm{wt}$. \% $\mathrm{NaCl}$ solution.

Figure 7: Bode (phase angle and modulus of impedance) plots for (a) welded joints and BM and (b) WM samples, respectively in 3.5 wt. \% $\mathrm{NaCl}$ solution.

Figure 8. EECs used to fit the EIS data: a) EEC for BM; b) EEC for welded joints and WM samples.

FIGURE 9: PP curves of BM, welded joints and WM samples In 3.5 wt. \% $\mathrm{NaCl}$ solution.

FIGURE 10: CLSM images a) before electrochemical experiments (sample was etched with Nital to make the microstructure visible), b) after polarisation experiments with corrosion products and c) PUL, d) CMT after removal of corrosion products.

FIGURE 11: a) SVET measurements of weld joint PUL; b) Appearance of the corroded surface taken in the end of the SVET test. The time showed on the top of each map represents the final time of each scan. In this sample one complete scan required $42 \mathrm{~min}$. In $0.1 \mathrm{wt}$. $\mathrm{NaCl}$ solution.

FIGURE 12: a) SVET measurements of weld joint CMT; b) Appearance of the corroded surface taken in the end of the SVET test. The time showed on the top of each map represents the final time of each scan. In this sample, one complete scan required $33 \mathrm{~min}$. In $0.1 \mathrm{wt} \% \mathrm{NaCl}$ solution. 
9. TABLES

Table 1: Chemical composition of the base metal and filler material.

\begin{tabular}{|c|c|c|c|c|c|c|c|c|c|}
\hline \multicolumn{10}{|c|}{ wt. \% } \\
\hline & C & $\mathrm{Si}$ & $\mathrm{Mn}$ & $\mathrm{Cr}$ & $P$ & $\mathrm{Nb}$ & $\mathrm{Ti}$ & $\mathrm{Al}$ & Others \\
\hline BM & 0.06 & 0.08 & 1.35 & 0.06 & 0.02 & 0.06 & 0.03 & 0.05 & $\begin{array}{l}\text { 0.001 V and Sn; } 0.010 \mathrm{Ni} \text {; } 0.009 \mathrm{~S} ; \\
0.005 \mathrm{Cu} ; 0.003 \mathrm{Co} ; 0.0001 \mathrm{~B} ; \\
0.004 \mathrm{Mo} \text {; bal. Fe }\end{array}$ \\
\hline filler & 0.09 & 0.85 & 1.53 & 0.03 & 0.03 & - & - & 0.001 & $\begin{array}{l}0.001 \mathrm{~V} ; 0.017 \mathrm{Ni} ; 0.013 \mathrm{~S} ; 0.141 \mathrm{Cu} \text {; } \\
0.003 \mathrm{Mo} \text {; bal. Fe }\end{array}$ \\
\hline
\end{tabular}

Table 2: Welding parameters of the GMAW process.

\begin{tabular}{ccccccccc}
\hline & Transfer & Current & Potential & Welding \\
Nomenclature & mode & $\begin{array}{c}\text { Speed } \\
(\mathrm{mm} / \mathrm{s})\end{array}$ & $\begin{array}{c}\text { Arc } \\
\%\end{array}$ & $\begin{array}{c}\text { Dynamic } \\
\%\end{array}$ & $\begin{array}{c}\text { Wire } \\
\text { speed } \\
(\mathrm{m} / \mathrm{mi} \\
\mathrm{n})\end{array}$ & $\begin{array}{c}\text { Heat Input } \\
(\mathrm{kJ} / \mathrm{mm})\end{array}$ & $\begin{array}{c}\text { Heat input } \\
\text { Intensity }\end{array}$ \\
\hline PUL & Pulsed & 187 & 22.7 & 5 & 8 & 0 & 6 & 0.72 \\
\hline CMT & CMT & 250 & 20 & 6 & 6 & 0 & 8.3 & $0.70 *$ \\
\hline
\end{tabular}

*ISO 15614-1:2017, a specification which qualifies welding procedures for metallic materials states that the Equation 1 is not suitable when power source with complex waveforms are used such as CMT. Therefore, HI value for CMT showed in Table 2 does not represent the real heat, but for simplicity equation 1 was used ${ }^{17}$.

Table 3: Prior austenite grain size in the CGHAZ.

\begin{tabular}{cc}
\hline Sample & $\mu \mathrm{m}$ \\
\hline PUL & $55.0 \pm 12.0$ \\
\hline CMT & $40.0 \pm 5.2$ \\
\hline
\end{tabular}

Table 4: Chemical composition of the CGHAZ and WM.

\begin{tabular}{ccccccc}
\hline \multirow{2}{*}{ Sample } & \multicolumn{7}{c}{ Composition wt. \% } \\
\cline { 2 - 7 } & $\mathrm{C}$ & $\mathrm{Si}$ & $\mathrm{Mn}$ & $\mathrm{Cr}$ & $\mathrm{Nb}$ & $\mathrm{Cu}$ \\
\hline CGHAZ_CMT & 0.34 & 0.04 & 1.30 & 0.01 & 0.09 & 0.06 \\
\hline CGHAZ_PUL & 0.85 & 0.02 & 1.39 & 0.02 & 0.07 & 0.03 \\
\hline WM_CMT & 0.20 & 0.35 & 1.39 & 0.02 & - & 0.02 \\
\hline WM_PUL & 0.21 & 0.31 & 1.29 & 0.02 & - & 0.09 \\
\hline
\end{tabular}


Table 5. Fitting parameters obtained using the EECs shown in Figure 8.

\begin{tabular}{|c|c|c|c|c|c|c|c|}
\hline Sample & $\begin{array}{c}\mathrm{R}_{\mathrm{e}} \\
\left(\Omega . \mathrm{cm}^{2}\right)\end{array}$ & $\begin{array}{c}\mathrm{Q}_{\mathrm{dl}} \\
\left(10^{-4} \mathrm{~F} \cdot \mathrm{cm}^{-2} \cdot \mathrm{s}^{\mathrm{n}-1}\right)\end{array}$ & $\mathrm{n}_{\mathrm{dl}}$ & $\begin{array}{c}\mathrm{R}_{\mathrm{ct}} \\
\left(\Omega . \mathrm{cm}^{2}\right)\end{array}$ & $\begin{array}{c}\mathrm{Q}_{\mathrm{ox}} \\
\left(10^{-4} \mathrm{~F} \cdot \mathrm{cm}^{-2} \cdot \mathrm{s}^{\mathrm{n}-1}\right)\end{array}$ & $\mathrm{n}_{\mathrm{ox}}$ & $\begin{array}{c}\mathrm{R}_{\mathrm{ox}} \\
\left(\Omega . \mathrm{cm}^{2}\right)\end{array}$ \\
\hline BM & 3.7 & 3.12 & 0.60 & 1296 & 2.68 & 0.84 & 11 \\
\hline $\begin{array}{c}\text { Welded } \\
\text { joint_PUL }\end{array}$ & 7.3 & 2.82 & 0.73 & 2408 & ---- & ---- & ---- \\
\hline $\begin{array}{c}\text { Welded } \\
\text { joint_CMT }\end{array}$ & 6.7 & 2.91 & 0.75 & 2281 & ---- & ---- & ---- \\
\hline WM_PUL & 5.5 & 5.86 & 0.78 & 1911 & ---- & --- & ---- \\
\hline WM_CMT & 4.7 & 6.67 & 0.79 & 2252 & ---- & --- & ---- \\
\hline
\end{tabular}




\section{FIGURE 1}

(a)

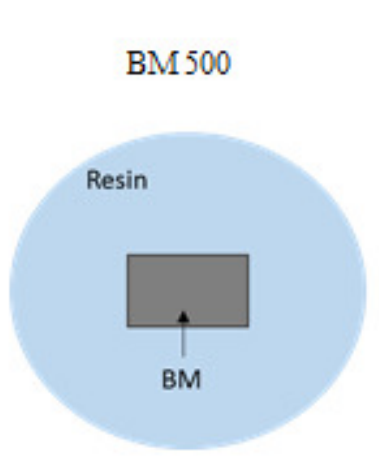

(b)

Welded joint_PUL

Welded joint_CMT

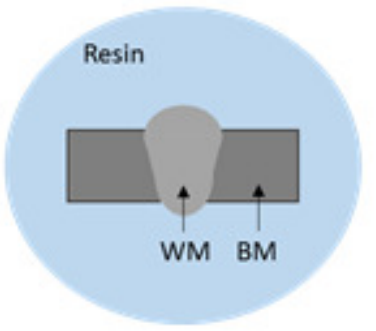

(c)

WM_PUL

WM_CMT

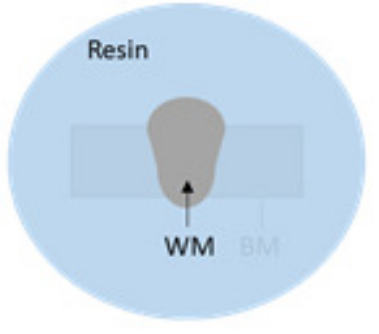

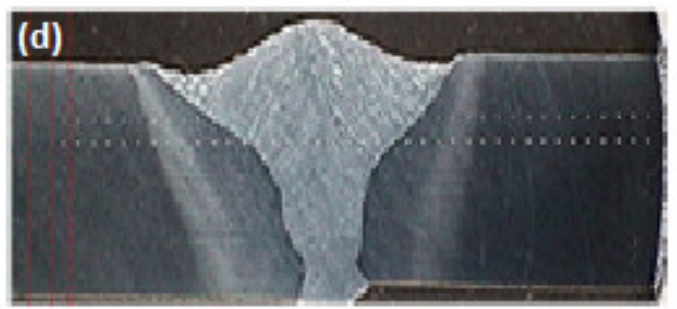




\section{FIGURE 2}

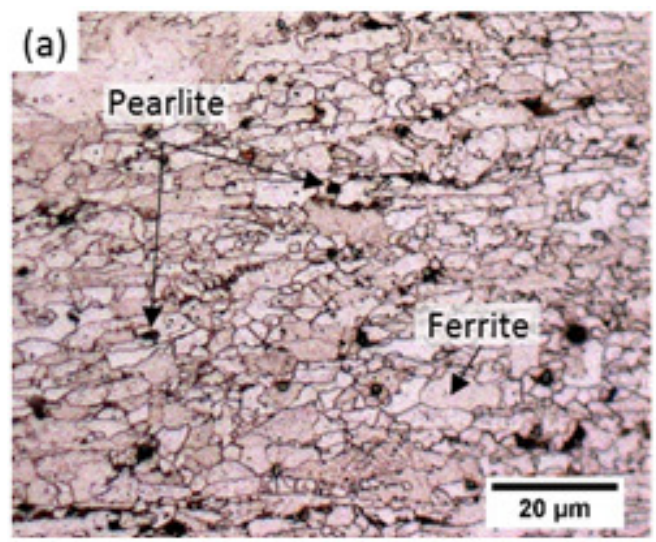

(c)

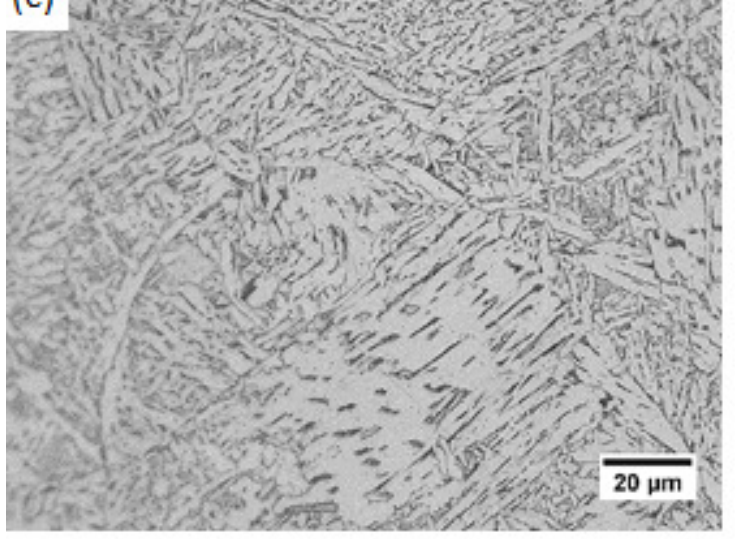

(e)

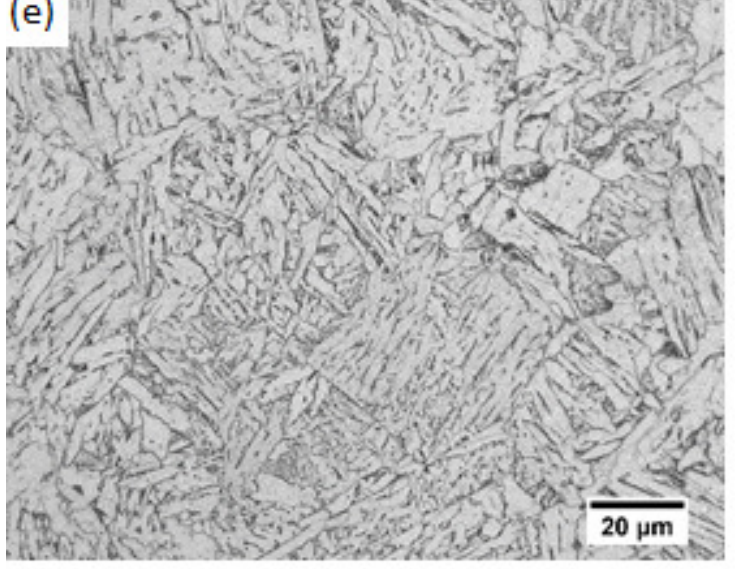

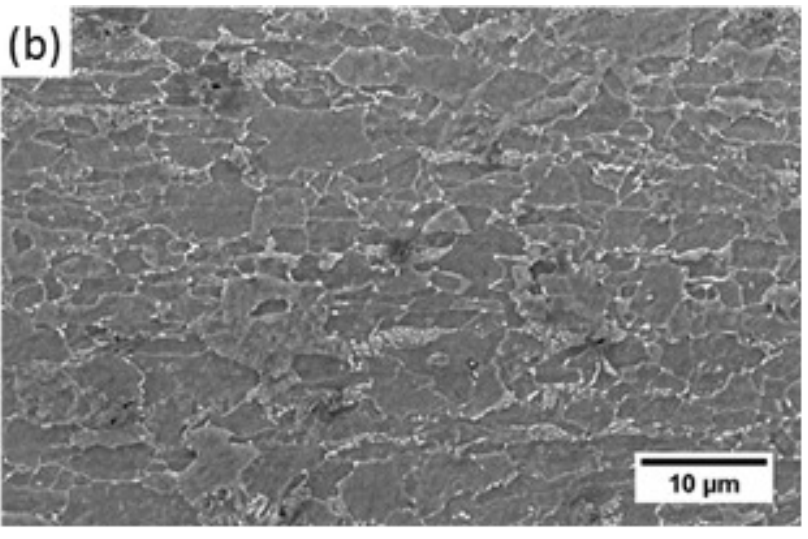
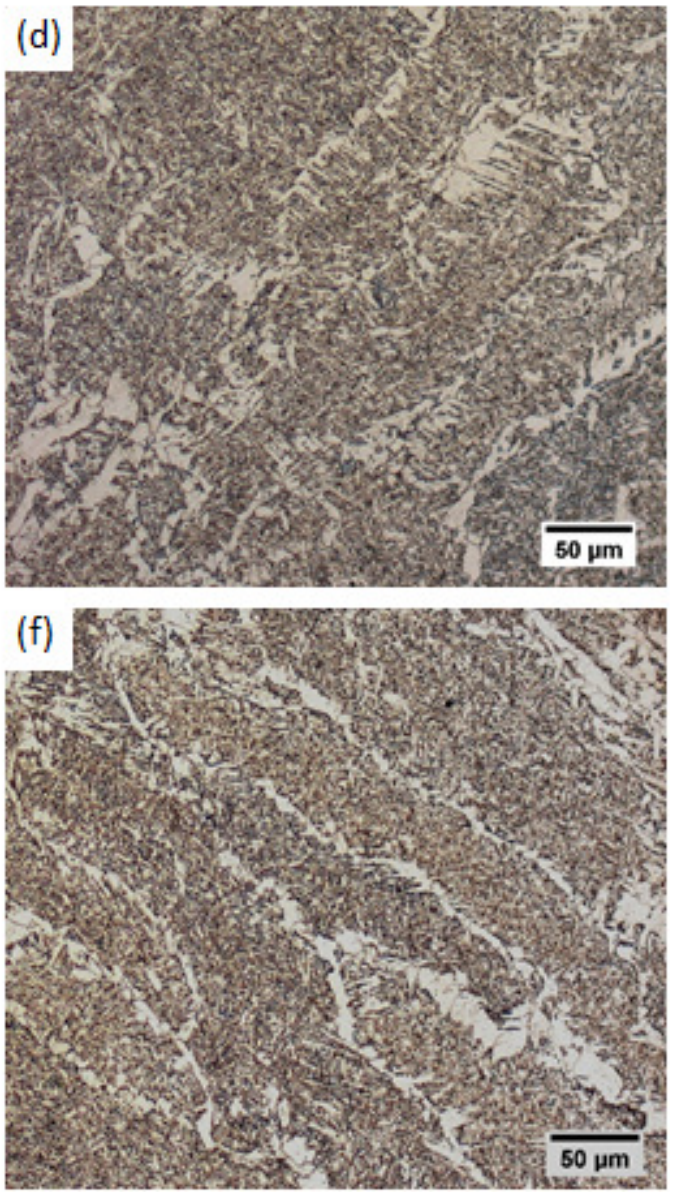


\section{FIGURE 3}

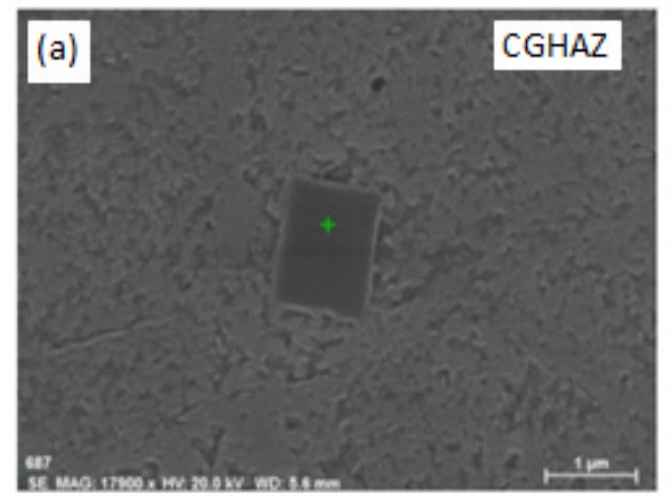

\begin{tabular}{cc}
\hline Element & $\mathrm{wt} \%$ \\
\hline $\mathrm{Fe}$ & 45.42 \\
\hline $\mathrm{Ti}$ & 38.64 \\
\hline $\mathrm{Nb}$ & 10.22 \\
\hline $\mathrm{N}$ & 8.72 \\
\hline $\mathrm{C}$ & 14.44
\end{tabular}
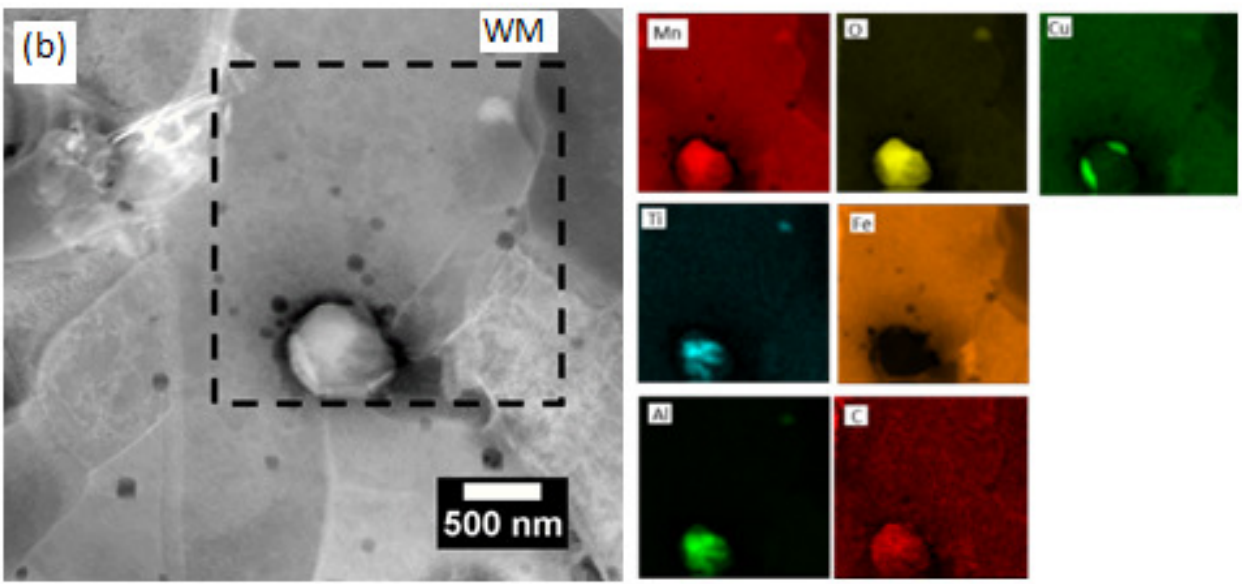
FIGURE 4
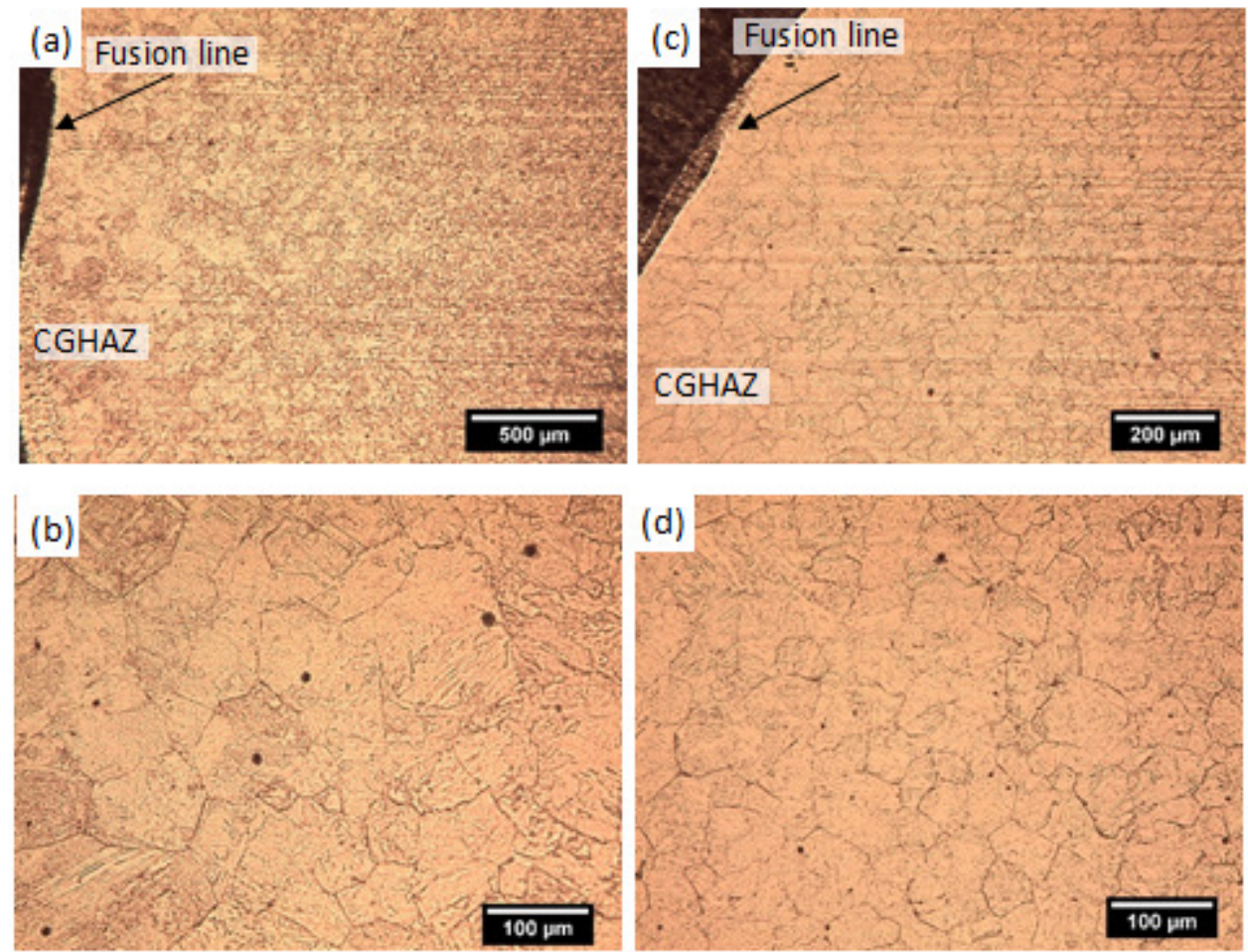
FIGURE 5

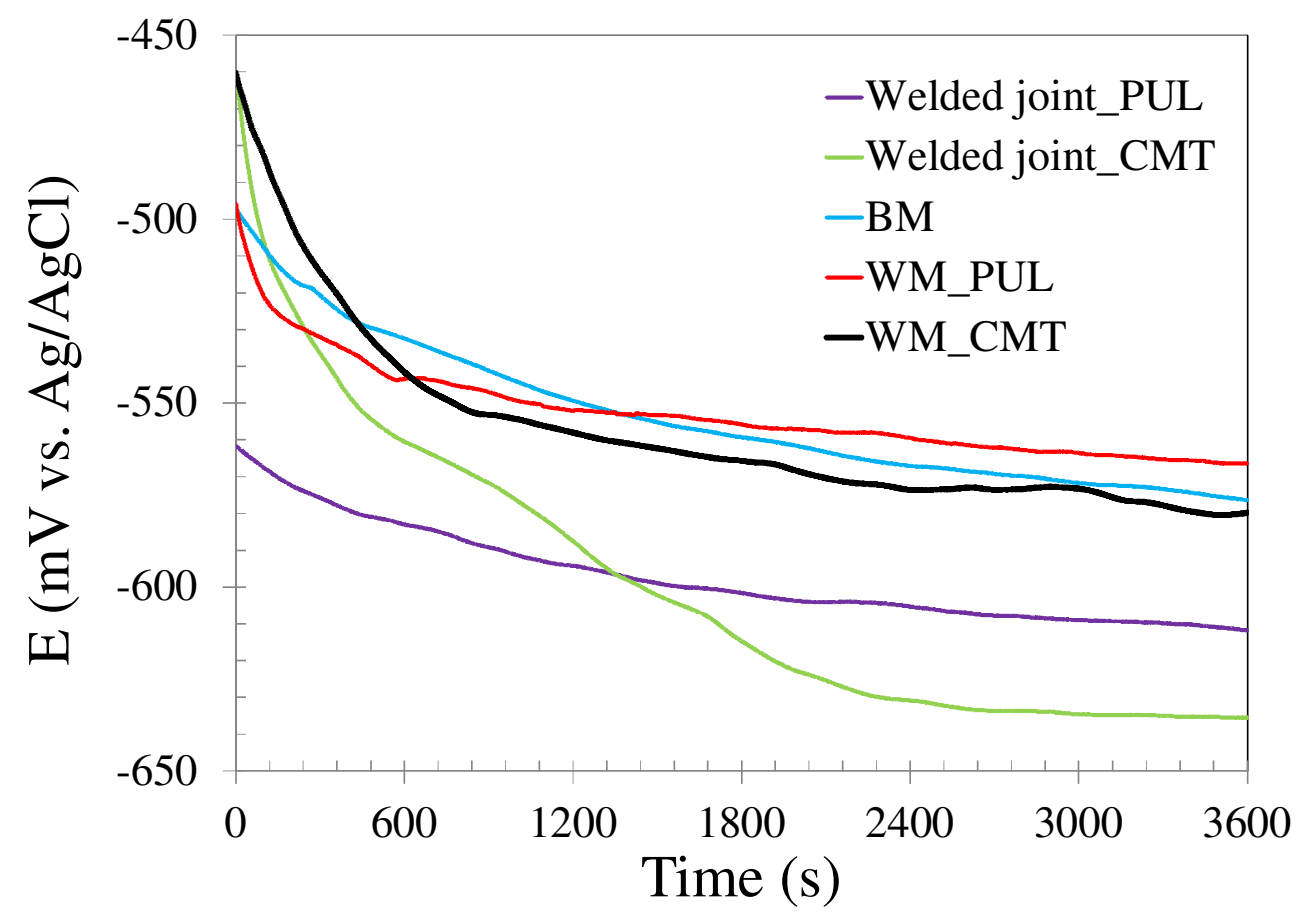


FIGURE 6
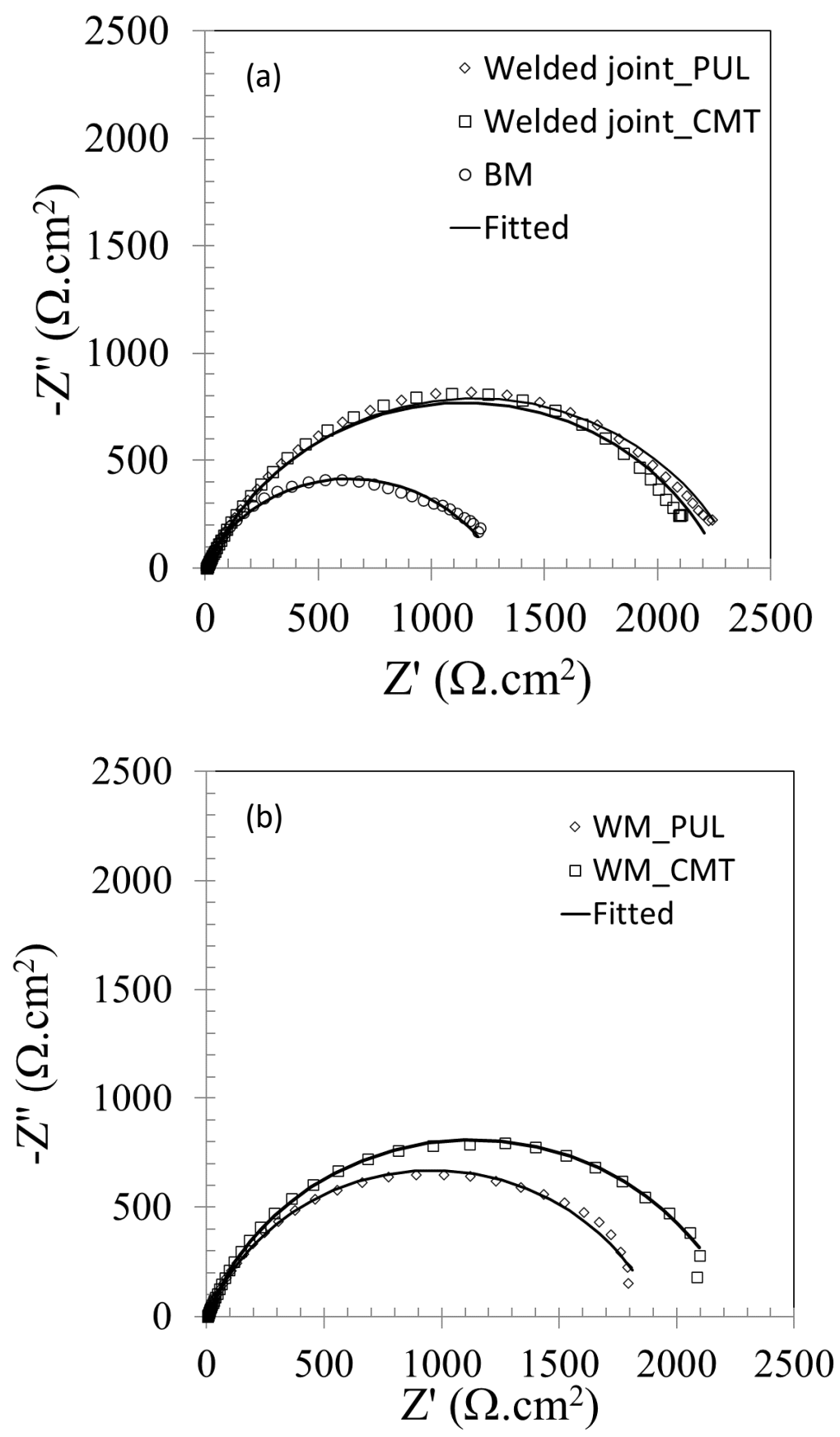
FIGURE 7
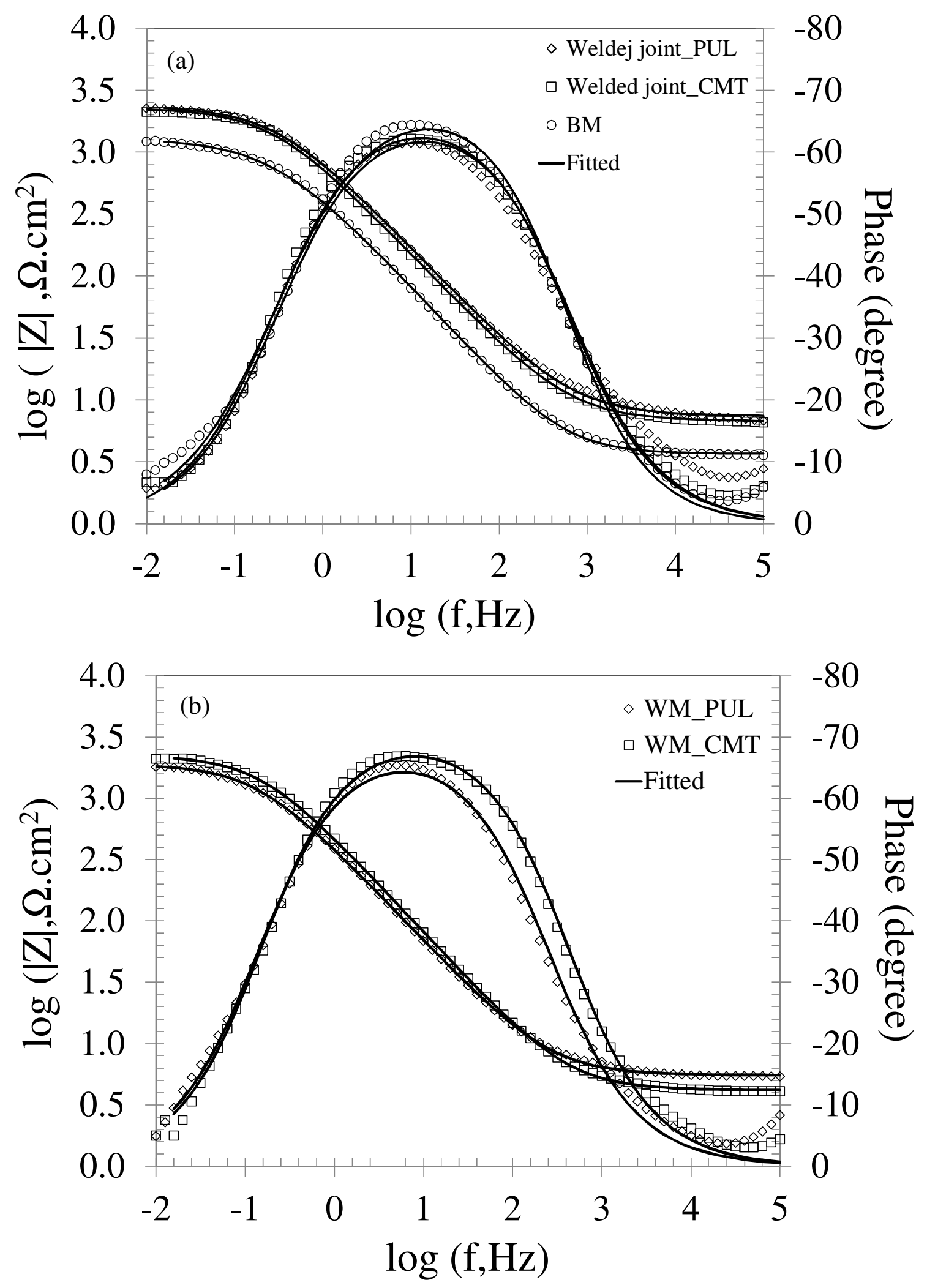
FIGURE 8
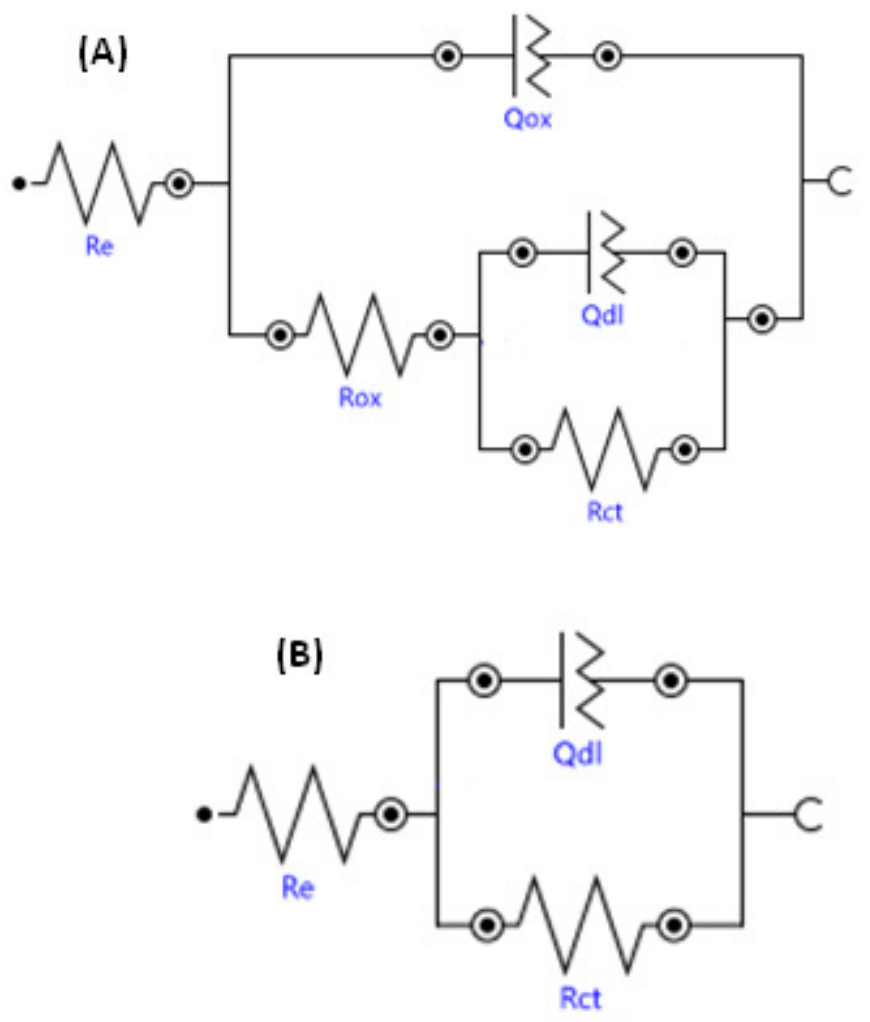
FIGURE 9

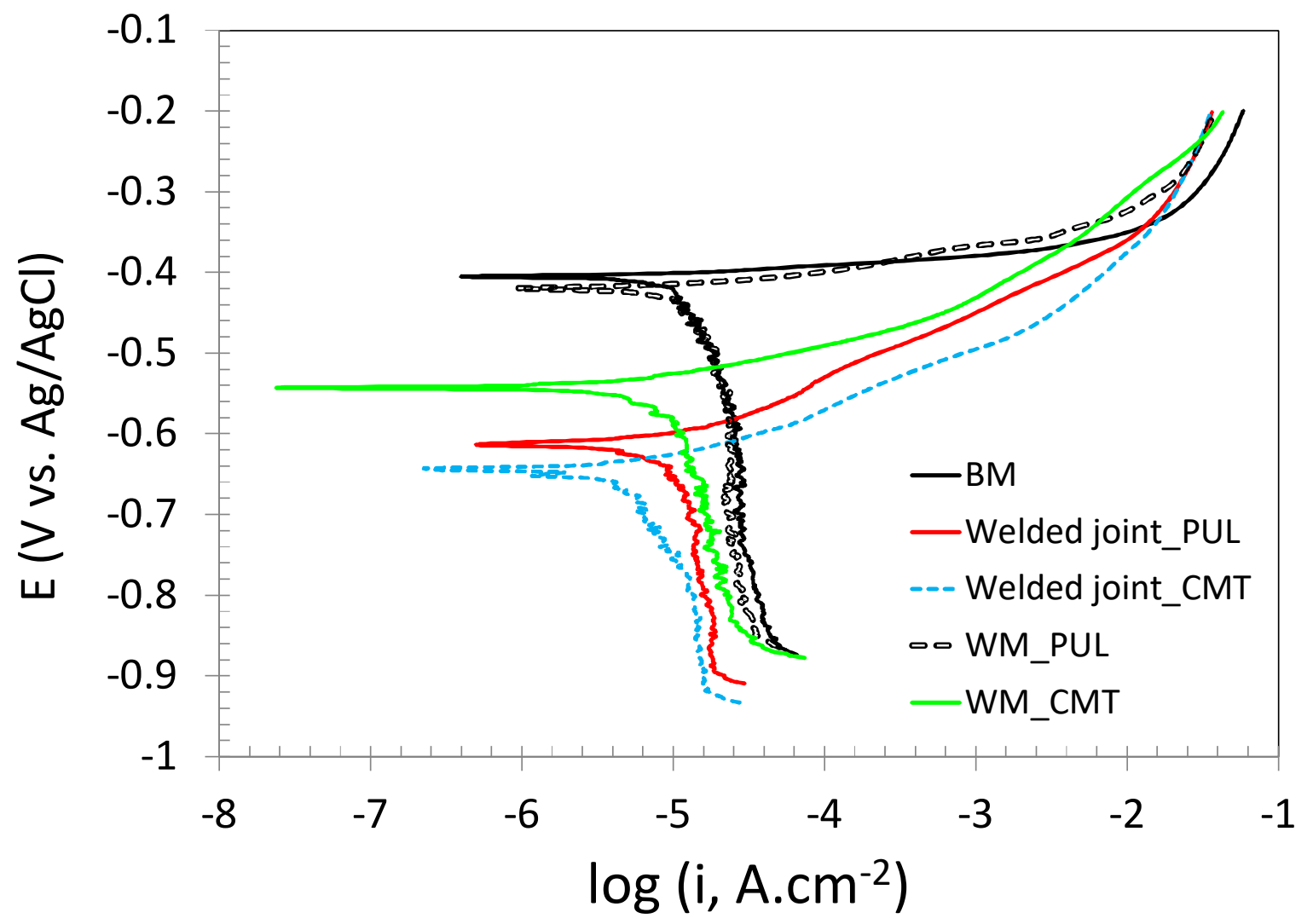




\section{FIGURE 10}
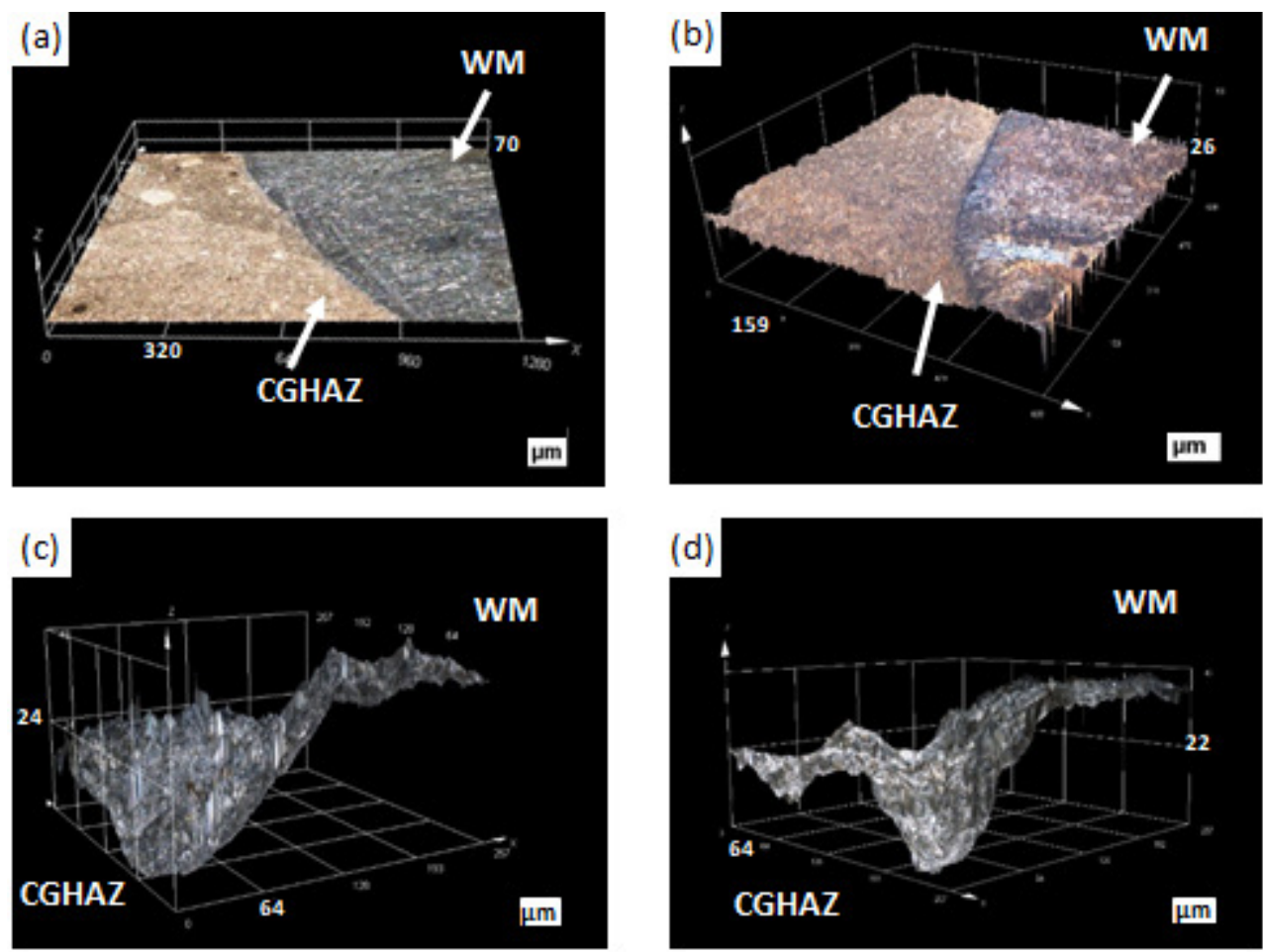


\section{FIGURE 11}

(a)
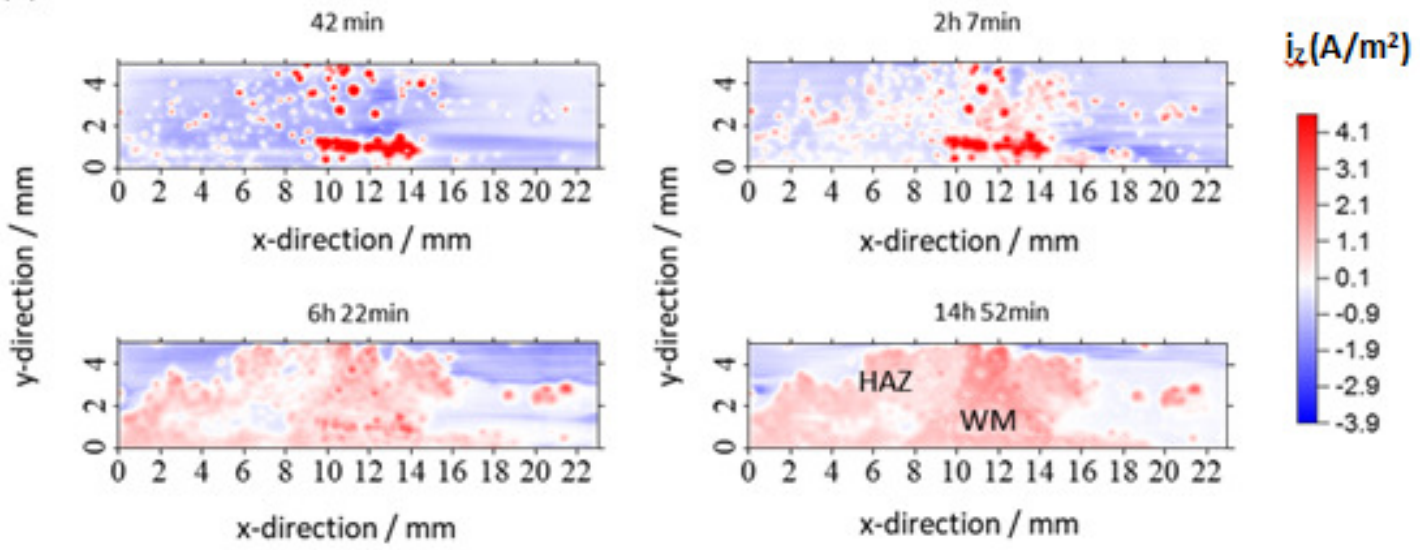

(b)

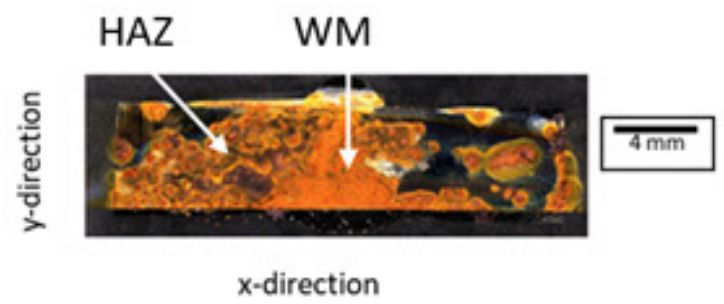




\section{FIGURE 12}

(a)
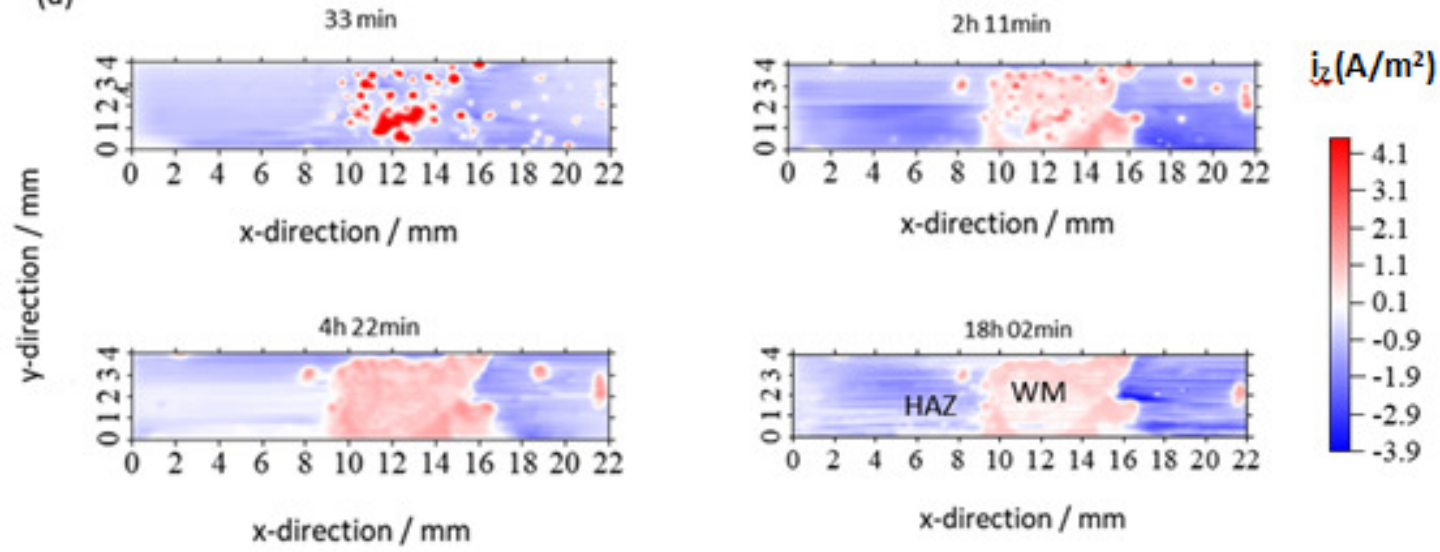

(b)

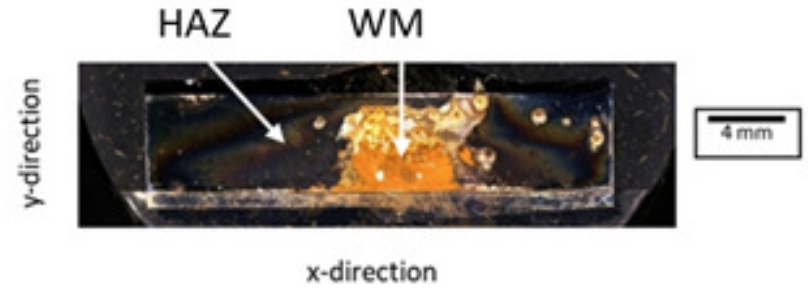

